\title{
VERIFICATION OF THE NEED TO DEVELOP A TOOL FOR SELECTING RESEARCH METHODS AND TECHNIQUES
}

\author{
Henryk DŹWIGOŁ \\ Silesian University of Technology, Faculty of Organization and Management; henryk.dzwigol@poczta.fm, \\ ORCID: 0000-0002-2005-0078
}

Purpose: The aim of this paper was to verify the necessity of devising a tool, method, procedure of selecting research methods and techniques for the research process, in order to increase the quality and reliability of the conducted research.

Design/methodology/approach: Within the scope of the research process a questionnaire was used, which was distributed in two forms to management theoreticians and practitioners. 401 management science theoreticians and 118 management practice representatives were examined.

Thus, the research problem was defined as follows: Is it necessary to develop (model, procedure, tool, approach) to the research process?

Findings: Conclusions derived from the completed analysis of national and foreign literature on management sciences indicate the need to perform a diagnosis. The diagnosis refers to the development of a procedure for selecting methods and techniques for the sake of research processes in management sciences.

The research carried out has identified the methods, procedures and approaches that are most relevant to the research process and its various components in management sciences. This makes it possible not only to determine the extent to which individual methods and techniques are used or combined, but also to identify certain regularities in the perception of the research process in this context and other variables that may influence the relevance of the appropriate choice of methods and techniques for the research process in management science in order to increase the reliability, level and quality of the research conducted.

Research limitations/implications: The methodological and method-related correctness of the presented work is confirmed by the answers to the questions included in the questionnaires. They most often highlighted barriers in planning and conducting scientific research, obstacles beyond the methodological ones, mistakes most often made in scientific research in management sciences, the applicability of results to business practice.

Practical implications: The conclusions of the research confirm that for the effective operation of the research process, it is necessary to develop a kind of 'behavioural algorithm' that will allow methods to be adapted to the posed research problem, once the gap has been defined, which will result in added value for practice.

This is also confirmed by reactions of management practitioners to these statements. $89 \%$ of the surveyed practitioners believe that there is a need to develop a model, procedure, tool or approach to support the appropriate selection of methods for the research process. 
Social implications: In management sciences it is genuinely easy to create 'new theories' that are not finally verified. A swift introduction of new, recommended management-related concepts and methods, as well as their rapid rejection resulted in negative organisational changes. It would be difficult to determine the reasons why the applied methods lack effectiveness. Was the failure triggered by an inadequate method used for a management process or by its unskilful implementation.

Originality/value: One verified the necessity of devising a tool, method, procedure of selecting research methods and techniques for the research process, in order to increase the quality and reliability of the conducted research. The elaborated methods, procedures or models were verified in practice with the aim of making the research reliable.

Keywords: process quality, research methods and techniques, management sciences.

\section{Introduction}

The modern science on organisations and management can, at the higher theoretical level (Arévalo, and Espinosa, 2015), especially in globalisation processes, reflect fundamental theories that would explain sources and ways in which changes in organisations are perceived; the theories resulting from: the life-cycle theory (Kessler, and Pozen, 2016), teleological theory (Graham, and Walton, 2018), dialectic theory (Putnam et al., 2016) and evolution theory (Drack, 2015; Bazaluk, 2015). These theories, seeming to give rise to the evolution theory, specify in detail change processes as a certain cycle of formalised events or actions (Dźwigoł, 2018).

In the course of development of the management-related science, one needs to underline the importance of a so-called initial impulse of the management practice. It is inextricably connected with the development of external conditions (nearer and further environment) and internal conditions (of particular companies as a reaction to changes occurring in the environment) (Bruke, 2017).

The clash of the methodological potential of management sciences with challenges of modern environment around science and companies allows to identify, in a better way, crucial problems which the management-related methodology needs to face (Bell et al., 2018; Bryman, 2016). The problems are:

- external conditions,

- breakthrough periods in their development, with consideration given to globalisation processes,

- anticipating of new,

- more efficient methodological solutions.

Thus, what is of key importance for the development of the science is a need to develop ways of applying methods being a part of pragmatic methodology (Harrison et al., 2017; Leech, 2016), diffusion of methodological paradigms identified particularly in the approach 
of the modern methodology in the management science (Dźwigoł, and Dźwigoł-Barosz, 2018; Bertrand, and Hughes, 2017) which would allow both theoreticians and practitioners to select a given research method in an easier and more efficient way (Bryman, 2006; Vaivio, and Sirén, 2010).

The analysis of methodological trends, i.e.: engineering, universalistic (administrative), interpersonal relations, operational studies, social systems, empirical, systemic, organisational games, situational approach, and cybernetic ones, induces new, radical changes (Palvia et al., 2015; Akhavan et al., 2016; Galport, and Galport, 2015). Currently supported by the psychological theory of organisations, sociological theory of organisations and by praxeological, modern, post-modern and process-related models, it gives rise to further scientific research (Coghlan, 2019). It is constantly supplemented by new ideas, generated by current needs of the reality (economic practice) and scientific achievements.

In the methodological scope, the process of searching for models of ideal concepts of selecting methods should reinforce the pragmatic methodology of management sciences by means of a new, unprecedented (in the source literature) application of the methodological approach, e.g. by G. Nadler (1967). It is also used to enhance the pragmatic methodology, as it encourages to create methods being directly applied in the practical aspect of management.

The traditional, hierarchic model of enterprise has been, so far, an aggregate of departments which, although acting under one determined goal for the entire company, have formulated their own operational trends (Chang, 2016). Nowadays, simple, network and orbital structures are favoured, where knowledge is regarded as an important asset (Jaakkola, and Hallin, 2018; Mykytas, 2018). It thus seems to be justified that both theoreticians (junior academics) and practitioners (managers and directors) should be provided with innovative research methods and techniques (most preferably online) that would facilitate the transfer of knowledge to the company and support the company's competitive edge, which, at the same time, would result from the implementation of a new strategy of economic development, e.g.: Industry 4.0 (Prause, 2015; Roblek et al., 2016).

It triggers the necessity to search, in a permanent way, for organisational changes that would take into consideration the life-cycle theory, the theological and dialectic theories, as well as evolution theory. Thus, one can assume that despite of ever-growing technical and technological development, a human being and their skills are still a strategic asset for companies. (Dźwigoł, et al., 2019).

Modern management science is focused on reality analysis (diagnostic function) (Labraca, 2017; Quinton, and Reynolds, 2018) and, on its basis, recommendations for practice (projective function) are formulated (Hair et al., 2019; Robbins, 2009). Therefore, it is necessary to use the methods in practice for research in fact-based management sciences and the classification used in the methodology of inductive sciences (Ares, and Varela, 2018). 
In order to diagnose the research problem comprehensibly and thoroughly, it is necessary to apply diverse research methods, providing an exhaustive answer to the posed question (Hair et al., 2019; Dźwigoł, 2018). The development of heterogenous cognitive methods, modelling or organisation management has an impact on the necessity to adopt an openminded approach, allowing or even encouraging to combine numerous approaches and methods. Hence some recommendations (Dźwigoł, 2018):

- a broad, multidimensional analysis of research methods in management sciences should be carried out,

- the methodological triangulation is a precondition for research processes in management sciences,

- qualitative methods within the scope of research process should be supported by case studies,

- verification of the developed methods, procedures or models in practice in order to make the research reliable is necessary, and before starting the research work, it is necessary to analyse the choice of selected methods in terms of the nature of the research,

- if the research process involves a process of combining methods, it is essential to analyse the impact of combining quantitative and qualitative methods on the research process.

The aim of this paper was to verify the necessity of devising a tool, method, procedure of selecting research methods and techniques for the research process, in order to increase the quality and reliability of the conducted research.

\section{Research method}

Conclusions derived from the completed analysis of national and foreign literature on management sciences indicate the need to perform a diagnosis. The diagnosis refers to the development of a procedure for selecting methods and techniques for the sake of research processes in management sciences. Thus, the research problem was defined as follows: Is it necessary to develop (model, procedure, tool, approach) to the research process?

With reference to the foregoing, the following research questions were posed:

P1. Is there any universalism of elaborated concepts, solutions to problems in the management sciences?

P2. Is it necessary to develop a model, procedure, tool or approach to the research process?

P3. Does the development of a model, procedure, tool or approach in the research process guarantee the reliability of results?

P4. Is it necessary to develop assumptions for building a research methodics? 
P5. Does the developed model, procedure, tool or approach to selecting methods in the research process have a significant impact on the quality and applicability of research results?

P6. Is verification of the developed methods, models and procedures a necessary condition for combining science and management practice?

In order to find answers to the posed research questions, the research study involved an anonymous questionnaire. The research study was carried out from October 2016 to April 2018.

The survey questionnaire consisted of three parts:

1. questions about the relevance of approaches, processes, methods and techniques in the research process in management sciences (5 questions).

2. questions concerning the raised problem of research process improvement (33 questions).

3. demographics (3 questions).

The structure of the questionnaire in the research part involved both open, rank questions, and questions based on the 5-point Likert scale ${ }^{1}$ (Dźwigoł, 2018).

The study covered theoreticians of management sciences and management practitioners, being a target group. As a result of the research effort, 401 representatives of management science theoreticians and 118 practitioners were surveyed.

\section{Research results}

The conducted research is of an introductory nature to the examined issue. It should be noted that the research does not exhaust the subject, but provides room for further discussions. It is worth noting what other factors may be examined in a given area, what other, more precise research based on the results already obtained may be carried out.

\footnotetext{
${ }^{1}$ The respondents were obliged to classify a particular answer as: strongly agree (5), agree (4), neither agree nor disagree (3), disagree (2), strongly disagree (1), with reference to each of the proposed assumptions.
} 


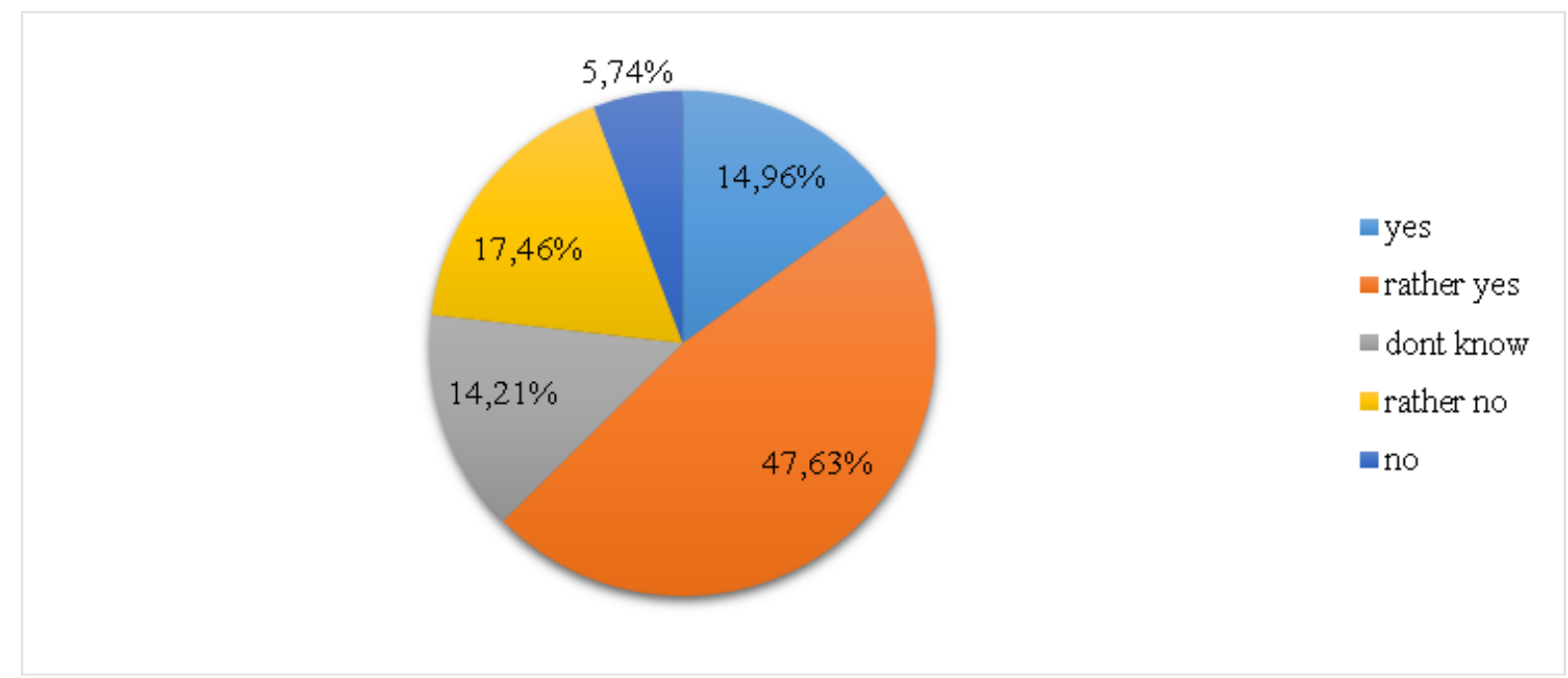

Figure 1. Is there any universalism of elaborated concepts, solutions to problems in the management sciences?

Analysing the results obtained, it can be clearly stated that $62.59 \%$ of the surveyed scientists believe that there is a universalism of developed concepts, solutions to problems in management sciences. A characteristic feature of the doctrine in management sciences is their low universality over time. The dynamics of changes in the turbulent economic environment directly affects changes in the approach to managing organisations in the short term. Moreover, companies operating in such an environment are forced to shift from traditional management to new, innovative approaches with greater freedom of decision-making, posing ever new challenges to both practitioners and management science theoreticians studying these phenomena.

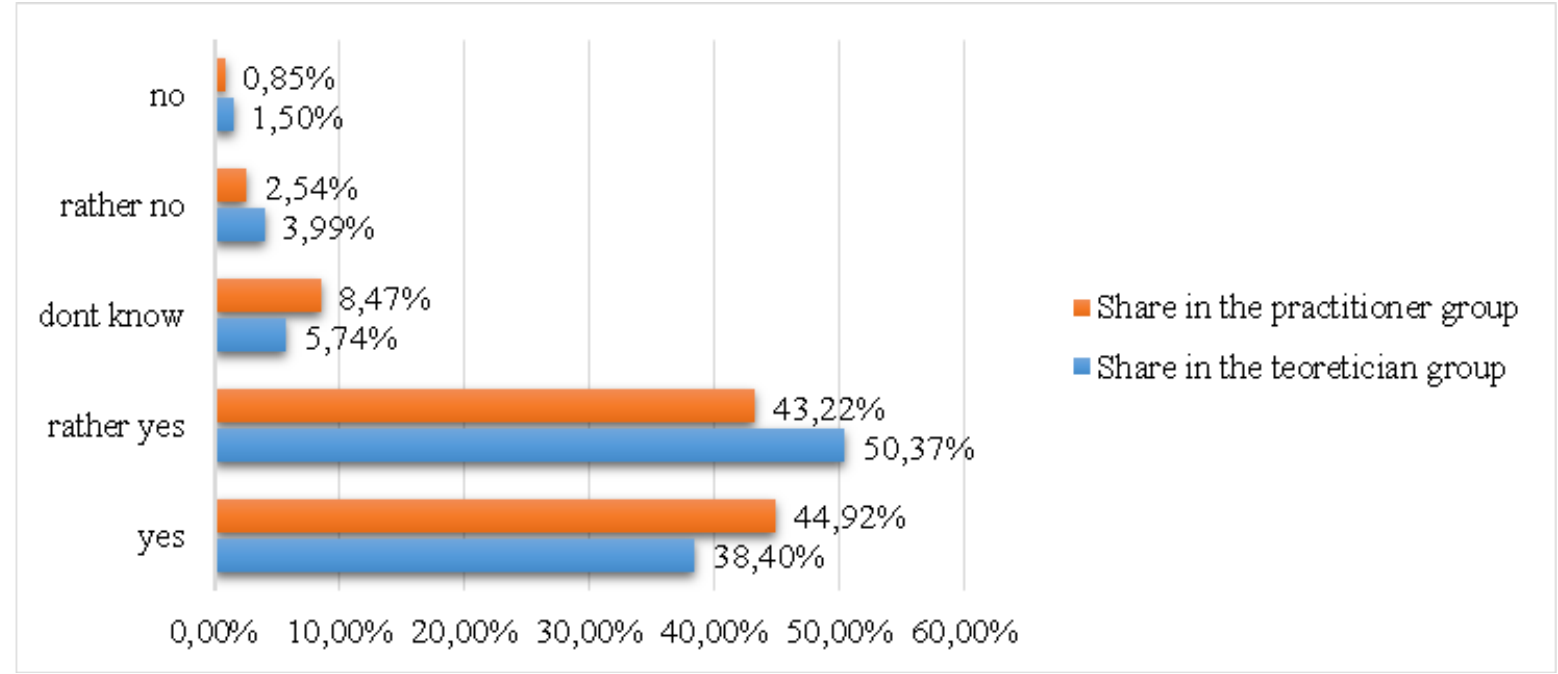

Figure 2. Is it necessary to develop a model, procedure, tool or approach to the research process? Author's own research.

$88.77 \%$ of researchers and $88.14 \%$ of management practitioners believe it is necessary to develop a model, procedure, tool or approach to the research process. Furthermore, it should be stressed that the percentage of research results in both groups is almost identical. 
In addition, the surveyed management practitioners most often indicated the following justifications to their answers:

- the methodics shows how certain issues are shaped - and, above all, it determines required assumptions, constraints and interdependencies. Moreover, it will allow for effective changes in the organisation;

- the development of a model for the selection of research methods and techniques will make it easier to start research work, especially for young scientists. The model should be open or modular with designated elements for each module.

The development of the model will directly contribute to the integration of the world of science and practice. Furthermore, the model, procedure, tool or approach to the research process will harmonise methodological approaches in the management sciences, thus increasing the reliability and relevance of the choice of individual methods, techniques and tools to the research process.

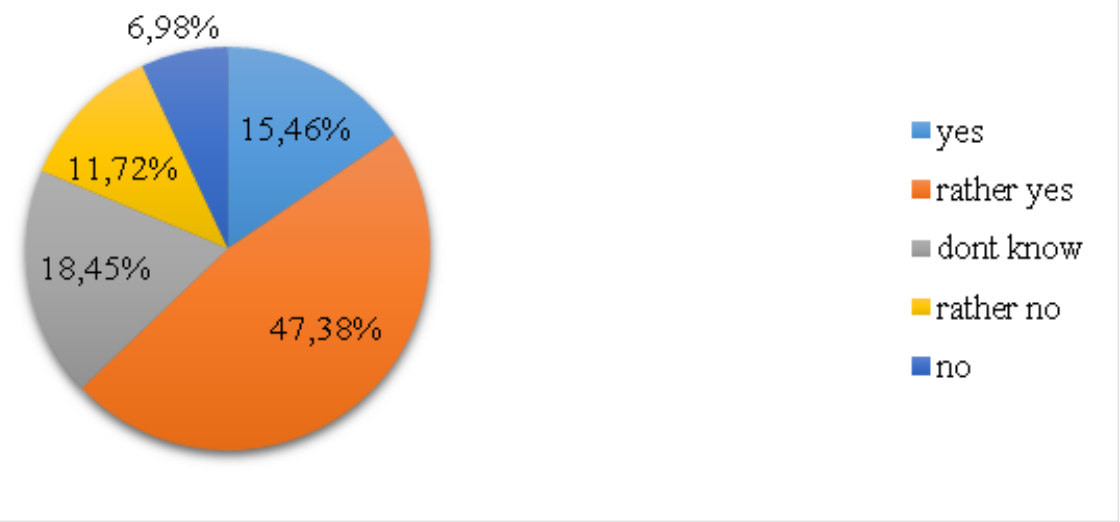

Figure 3. Does the development of a model, procedure, tool or approach in the research process guarantee the reliability of the results? Author's own research.

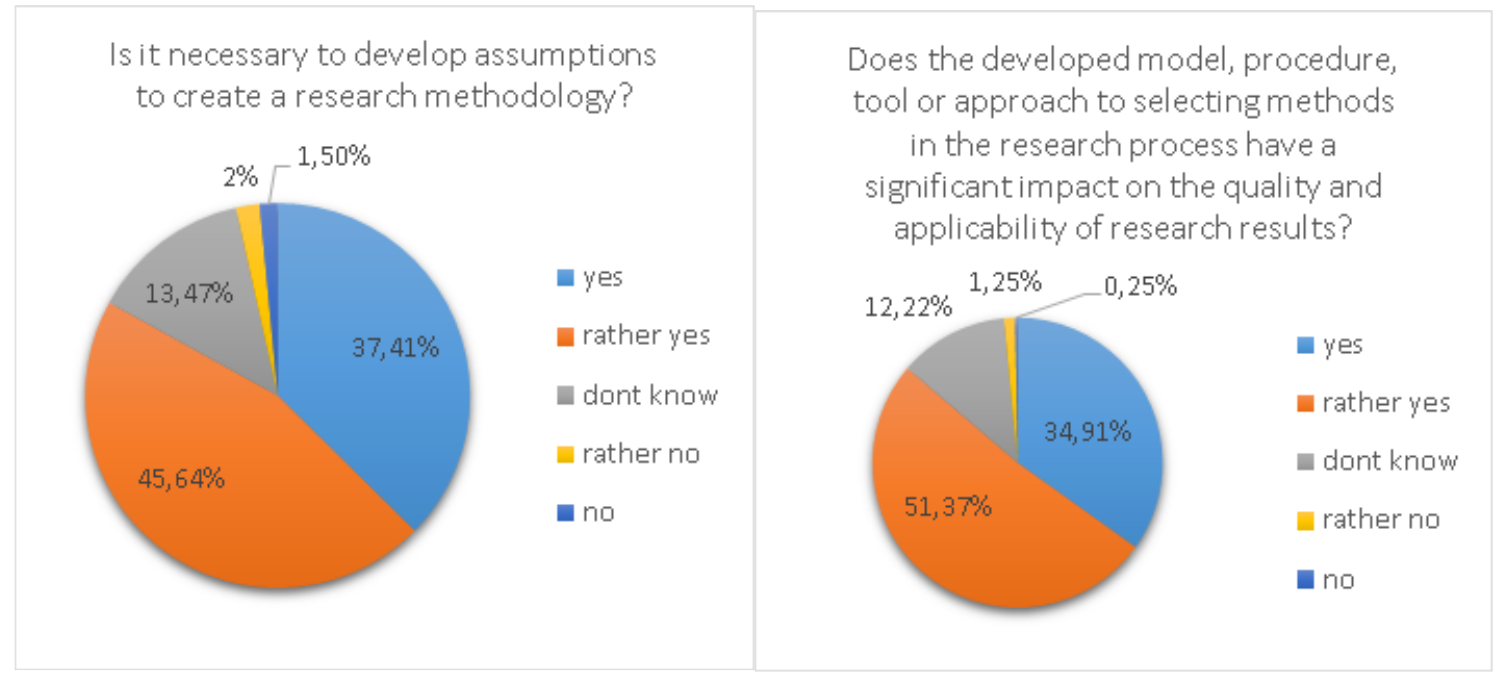

Figure 4. Aggregate research results - the need to develop (model, procedure, tools, approach) to the research process. Author's own research. 
$62.84 \%$ of researchers believe that developing a model, procedure, tool or approach in the research process guarantees the reliability of results. However, $18.70 \%$ do not agree with this statement, stressing that the key factor is the reliability of the conducted research. However, it should be noted that the reliability of research is not only the way it is carried out, but also the appropriate choice of the subject, the purpose of the research, research methods and techniques, etc. Moreover, research triangulation with an appropriate combination of qualitative and quantitative methods increases the reliability of results. In management sciences one, through scientific research, aims to discover new regularities, methods or ways to increase the efficiency and effectiveness of the management process. The problem lies in the overproduction of research findings and publications, being useless or not fully valuable. Research should not start when the questions asked are socially irrelevant or even too simple.

By analysing the obtained results, it becomes explicitly clear that:

- $83.05 \%$ of the surveyed scientists believe that it is necessary to develop assumptions for building research methodics.

- $86.28 \%$ of researchers believe that the developed model, procedure, tool or approach of method selection in the research process has a significant impact on the quality and applicability of research results. Methodological stringency is crucial but not the most important criterion for evaluating the research. It emphasises the quality of the researcher's skills, the quality of the research and the reliability of results. Management science has exactly the same objective as any other field of science, namely to provide solid, reliable knowledge (Thompson, 1956) based on the reliability, transferability, integrity and corroboration of the research being conducted.

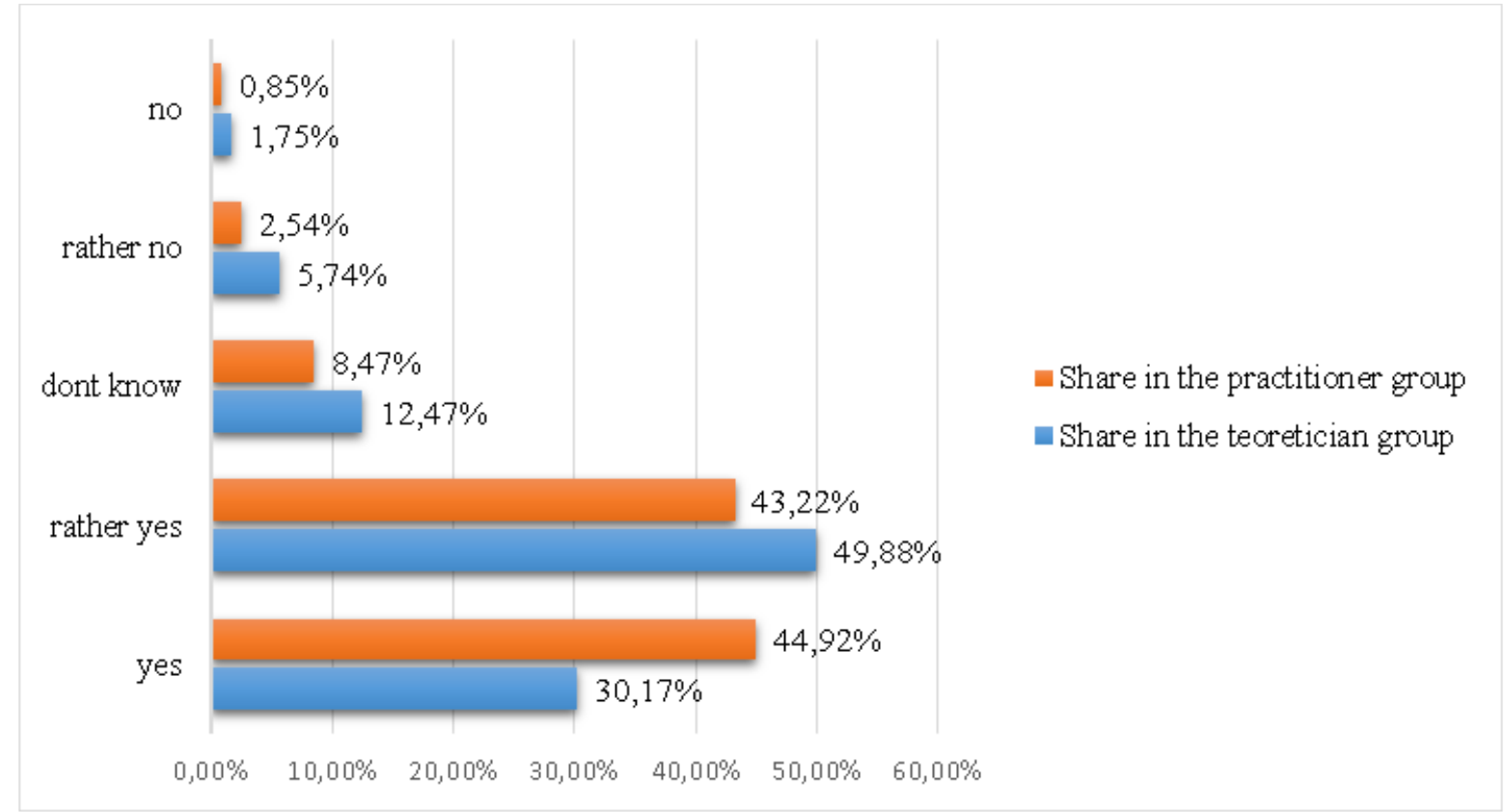

Figure 5. Is the verification of developed methods, models or procedures a prerequisite for combining learning and management practice? Author's own research. 
$80.05 \%$ of interviewed scientists and $88.14 \%$ of practitioners believe that the verification of elaborated methods, models or procedures is a prerequisite allowing to combine practical and theoretical aspects of management sciences? Concepts related to management sciences derive from the observation of organizations and are generally of a secondary nature to the economic reality. Moreover, the integration of science and business practice stimulates creativity, innovativeness, modernity and professionalism of the research process. It is also crucial in such a process to draw the theoreticians' attention to the needs arising from business practice, as management science is a blend of few specific concepts, tools and methods, often mutually exclusive, which are difficult to be applied in practice.

\section{Summary and research conclusions}

The aim of this paper was to verify the necessity of devising a tool, method, procedure of selecting research methods and techniques for the research process, in order to increase the quality and reliability of the conducted research.

The aim of the management science is to continuously discover or formulate new research methods and techniques. Management has accompanied people from the beginning of their existence. In practice it is used every day, by every human being. In management sciences it is genuinely easy to create 'new theories' that are not finally verified. A swift introduction of new, recommended management-related concepts and methods, as well as their rapid rejection often result in negative organisational changes within enerprises. It would be difficult to determine the reasons why the applied methods lack effectiveness. Was the failure triggered by an inadequate method used for a management process or by its unskilful implementation.

The vast majority of management-related scientists $(89 \%)$ participating in the questionnaire stated that it is necessary to develop a model, procedure, tool, approach to the research process. Moreover, a large proportion of respondents $(86 \%)$ believe that the developed model, procedure, tool or approach as to selecting methods to the research process significantly affects the quality and practical use of research results.

This is also confirmed by reactions of management practitioners to the above statements. $89 \%$ of the interviewed practitioners believe that there is a need to develop a model, procedure, tool or approach in order to support a proper selection of methods for research processes.

The answers to the questionnaires confirm the methodological and method-related correctness of the presented work. They most often highlighted barriers in planning and conducting scientific research, obstacles beyond the methodological ones, mistakes most 
often made in scientific research in management sciences, the applicability of results to business practice.

For the effective operation of the research process, it is necessary to develop a kind of 'behavioural algorithm' that will allow methods to be adapted to the posed research problem, once the gap has been defined, which will result in added value for practice. One distinguishes, within the scope of management sciences, the following types of added value: model, procedure, recommendation, tool. Should at least one of these types be welldeveloped, it shall result in a visible improvement of cooperation between theory and practice in modern enterprises.

Thanks to the conducted research on identifying methods, procedures and approaches to be selected, one was able to find out which of these are the most relevant to the research process and its individual elements within management sciences. This allows not only to determine the extent to which individual methods and techniques are used or combined, but also to identify certain regularities in the perception of the research process in this context and other variables that may influence the relevance of the appropriate choice of methods and techniques for the research process in management science in order to increase the reliability, level and quality of research conducted.

\section{References}

1. Akhavan, P., Ebrahim, N.A., Fetrati, M.A., \& Pezeshkan, A. (2016). Major trends in knowledge management research: a bibliometric study. Scientometrics, 107(3), 12491264.

2. Ares, G., and Varela, P. (Eds.) (2018). Methods in Consumer Research, Volume 1: New Approaches to Classic Methods. UK: Woodhead Publishing, Elsevier, Duxford.

3. Arévalo, L.E.B., \& Espinosa, A. (2015). Theoretical approaches to managing complexity in organizations: A comparative analysis. Estudios Gerenciales, 31(134), 20-29.

4. Bazaluk, O. (2015). The theory of evolution. Philosophy and Cosmology, 15(15), 25-33.

5. Bell, E., Bryman, A., \& Harley, B. (2018). Business research methods. Oxford University Press.

6. Bertrand, I., \& Hughes, P. (2017). Media research methods: Audiences, institutions, texts. Macmillan International Higher Education.

7. Bryman, A. (2006). Integrating quantitative and qualitative research: How is it done? Qualitative Research, 6(1), 3-37, https://doi.org/10.1177/1468794106058877.

8. Bryman, A. (2016). Social research methods. Oxford University Press.

9. Burke, W.W. (2017). Organization change: Theory and practice. Sage Publications. 
10. Chang, J.F. (2016). Business process management systems: strategy and implementation. Auerbach Publications.

11. Coghlan, D. (2019). Doing action research in your own organization. SAGE Publications Limited.

12. Drack, M. (2015). Ludwig von Bertalanffy's organismic view on the theory of evolution. Journal of Experimental Zoology Part B: Molecular and Developmental Evolution, 324(2), 77-90.

13. Dźwigoł, H., \& Dźwigoł-Barosz, M. (2018). Scientific research methodology in management sciences. Financial and credit activity: problems of theory and practice, 2(25), 424-437.

14. Dzwigol, H., Aleinikova, O., Umanska, Y., Shmygol, N., \& Pushak, Y. (2019). An Entrepreneurship Model for Assessing the Investment Attractiveness of Regions. Journal of Entrepreneurship Education, 22(SI1), 1-7.

15. Galport, M., \& Galport, N. (2015). Methodological trends in research on evaluation. New Directions for Evaluation, 148, 17-29.

16. Graham, E., \& Walton, H. (2018). Theological reflection: methods. scm Press.

17. Hair, J.F., Page, M., and Brunsveld, N. (2019). Essentials of Business Research Methods. New York: Routledge, https://doi.org/10.4324/9780429203374.

18. Harrison, H., Birks, M., Franklin, R., \& Mills, J. (2017, January). Case study research: Foundations and methodological orientations. Forum Qualitative Sozialforschung/ Forum: Qualitative Social Research, Vol. 18, No. 1.

19. Jaakkola, E., \& Hallin, A. (2018). Organizational structures for new service development. Journal of Product Innovation Management, 35(2), 280-297.

20. Kessler, J.K., \& Pozen, D.E. (2016). Working Themselves Impure: A Life Cycle Theory of Legal Theories. The University of Chicago Law Review, 1819-1892.

21. Labarca, C. (2017). Qualitative Research for beginners. Maracaibo, Venezuela.

22. Leech, G.N. (2016). Principles of pragmatics. Routledge.

23. Mykytas, M., Terenchuk, S., \& Zhuravska, N. (2018). Models, methods and tools of optimizing costs for development of Clusterized organizational structures in construction industry. International Journal of Engineering \& Technology, 7(3.2), 250-254.

24. Nadler, G. (1967). Work Systems Design: The Ideals Concept. Irwin, Homewood.

25. Palvia, P., Daneshvar Kakhki, M., Ghoshal, T., Uppala, V., \& Wang, W. (2015). Methodological and topic trends in information systems research: A meta-analysis of IS journals. Communications of the Association for Information Systems, 37(1), 30.

26. Prause, G. (2015). Sustainable business models and structures for Industry 4.0. Journal of Security \& Sustainability Issues, 5(2).

27. Putnam, L.L., Fairhurst, G.T., \& Banghart, S. (2016). Contradictions, dialectics, and paradoxes in organizations: A constitutive approach. The Academy of Management Annals, 10(1), 65-171. 
28. Quinton, S., Reynolds, N. (2018). Understanding Research in the Digital Age. London: SAGE Publications Ltd.

29. Robbins, D. (2009). Understanding research methods. A guide for the public and nonprofit manager. Boca Raton, USA: CRC Press, Taylor \& Francis Group.

30. Roblek, V., Meško, M., \& Krapež, A. (2016). A complex view of industry 4.0. Sage Open, 6(2), 2158244016653987.

31. Thompson, J.D. (1956) On Building an Administrative Science. Administrative Science Quarterly, Vol. 1, No. 1, 102-111.

32. Vaivio, J., \& Sirén, A. (2010) Insights into method triangulation and "paradigms" in interpretive management accounting research. Management Accounting Research, 21(2), 130-141, https://doi.org/10.1016/j.mar.2010.03.001. 